\title{
Things on which a computer science engineer should focus on
}

\author{
Divya, P.Deepthi \\ (IT, G. Pullaiah college of engineering and technology, India)
}

\begin{abstract}
One of the evergreen course in engineering is the computer science engineering.It is the one which is ruling the entire world. To continue its journey successfully in future generations ,the present generation students should play a major role by developing good softwares, by focusing on some of the important and necessary skills which leads to the success.
\end{abstract}

\section{Introduction}

What should students really focus on? A question that migrates in the students mind all the time, here is a solution to it. Imagine students in $2^{\text {nd }}$ and $3^{\text {rd }}$ year of their degree . They will spend few years finishing college and few years just learning their ropes at their jobs. So, it takes 5years to start their career. How will the software technology world will be at that time, and what are the skills a student must acquire right to thrive? Here, are the list of skills

\section{Skills A Computer Science Student Should Posses}

2.1. Communication As soon as the student gets admitted in engineering institution their focus remains on placements and surroundings. The first thing an engineer must focus is on fluency in English. You must check yourself how fluent you are in English language. English is one of the six official languages of the united nations. When people of different countries meet ,their common medium of communication is English.

2.2. Software Usability As IT touches more and more people, less and less of them will be "computer savvy" and less and less of them will view computing devices as something that needs to be learnt. The products that will succeed will be the one 's that are easy to use. And making something easy to use is very difficult. A lot of theory and bundle of well defined algorithms and practice makes things easy.

2.3. Computer science fundamentals This will never go out of fashion, but students coming out of the colleges appear it to be as a neglected area. Too much emphasis on specific programming languages and technologies is a mistake, whatever the future holds you must be served by knowing the basics of it. Learn data structures and algorithms. Even if you have a small clarifications on particular topic hit books still you get it clarified. Understanding basics is important, if you learn C-language and if you don't understand the concept of pointers, etc it is a disadvantage.

2.4. Presentation Skills This is not a technical skill, but is an important skill of an computer science student. You must treat presentation as important or more important than your program, design and algorithm. While presenting you must think on what users want to know instead of telling what you know or what you want to tell. You must be a good story teller to create an interest on what you say. For example while your presentation if you have committed any mistake in your presentation at that time support your statement by explaining the problems faced by it before listeners recognize your mistake. First and foremost thing is be confident while your presentation whether it is correct or wrong.

2.5. Economics Scott Adams, the creator of Dilbert says "When you have a working knowledge of economics, its like having a mild super power". Basically , if you understand the fundamentals of economics, you can see and understand what drives people and technologies and success and failure. 


\section{Conclusion}

A good program developer can become a good software engineer. To become a good programmer and a perfect engineer practicing of programming languages every day, giving presentations frequently and knowing about the updated softwares are important. So, focus on the remedies and be a successful engineer. 